\title{
Hemoglobinopati, Asetil Salisilik Asit Kullanimi Ve Üreminin İmmünoturbidimetrik Ve HPLC Hemoglobin A1c Ölçümleri Üzerine Etkileri
}

\author{
Gülçin Şahingöz Erdal ${ }^{1}$, Murat Koşer ${ }^{2}$, Pınar Kasapoğlu ${ }^{3}$, Nilgün Işıksaçan ${ }^{3 *}$ \\ ${ }^{1}$ Bakırköy Dr Sadi Konuk Eğitim ve Araştırma Hastanesi İç Hastalıkları Kliniği, İstanbul Türkiye \\ ${ }^{2}$ Silivri Açık Ceza İnfaz Kurumu Hastanesi, Biyokimya Kliniği İstanbul, Türkiye \\ ${ }^{3}$ Bakırköy Dr Sadi Konuk Eğitim ve Araştırma, Hastanesi, Biyokimya Kliniği İstanbul, Türkiye
}

email: gulcinctf@hotmail.com, muratkoser@hotmail.com, proxy75@hotmail.com,nisiksacan@gmail.com

Orcid:0000-0001-5815-5847

Orcid:0000-0001-7102-0875

Orcid:0000-0003-1703-2204

Orcid:0000-0002-0230-6500

*Sorumlu Yazar / Corresponding Author: Sorumlu Yazar: Nilgün Işıksaçan

\author{
Gönderim Tarihi / Received: 28.05.2019 \\ Kabul Tarihi / Accepted: 08.08.2019 \\ DOI: $10.34087 /$ cbusbed.558634
}

\begin{abstract}
Amaç: Tip 2 Diabetes Mellitus (T2DM) en sık endokrin hastalıktır. Yüksek glikolize hemoglobin (HbA1c) düzeylerinin kardiyovasküler hastalıklarda $(\mathrm{KVH})$ risk faktörü olduğu ve KVH'ların da diyabetik hastalarda ölüm ve sakatlığa neden olduğu bilinmektedir. HbA1c düzeylerinin doğru ölçülmesi, hastaların tanı ve tedavi süreçlerinin değerlendirilmesinde son derece önemli rol oynamaktadır.

Ülkemizde başta talasemi minör olmak üzere hemoglobin varyantları yaygın olarak görülmektedir. Diyabetin kardiyovasküler etkileri nedeniyle de asetilsalisilikasit (ASA) sıklıkla diyabetik hastalar tarafından kullanılmaktadır. Diyabetik nefropati ise son dönemde hemodiyaliz gerektiren böbrek yetmezliğine ve üremiye neden olmaktadır. Bu çalışmada immünoturbidimetri ve yüksek performanslı sıvı kromatografi (HPLC) yöntemlerinin 3 hasta grubunda HbA1c düzeylerini ölçmek üzere karşılaştırılması amaçlanmıştır.

Gereç-Yöntem: Bu çalışmaya her biri 20 hastadan oluşan üç grup dahil edilmiştir. Bu çalışmaya 20'şer kişilik 3 hasta grubu dahil edilmiştir. İlk grup hemoglobin elektroforezi kullanılarak "hemoglobinopati" tanısı alan hastalardan, ikinci grup en az 6 aydır günde $100 \mathrm{mg}$ veya üzerinde ASA alan hastalardan ve üçüncü grup kronik hemodiyalize giren hastalardan oluşmaktadır. Hastalardan alınan EDTA içeren tüplere toplanan venöz kan örnekleri, Premier Hb 9210 (Trinity Biotech -USA) ve Cobas c501 (Roche -Almanya) cihazları kullanılarak analiz edilmiştir. Sonuç: Her 3 grupta immünoturbidimetri ile HPLC yöntemi karşılaştırıldığında grupların içinde HbA1c düzeyleri arasında anlamlı bir istatistiksel fark bulunamamıştır $(\mathrm{p}=0,462, \mathrm{p}=0,065 \mathrm{p}=0,062)$.

Tartışma: İmmünoturbidimetri ve HPLC, HbA1c ölçümlerinde yaygın olarak kullanılan yöntemlerdendir. İmmünoturbidimetrik yöntemin $\mathrm{HbA1c}$ ölçümlerinde HPLC yöntemi ile arasında güçlü bir korelasyon olduğu gösterilmiştir. HbA1c analizini etkileyebilecek hastalıklar ve ilaçlar göz önünde bulundurulmalıdır.
\end{abstract}

Anahtar Kelimeler: Hba1c, HPLC, Immünoturbidimetri, Hemoglobinopati, Üremi, ASA.

\footnotetext{
Abstract

Background: Type II Diabetes Mellitus(T2DM) is the most frequent endocrin disease. Elevated HbA1c level is reported as a risk factor in cardiovascular diseases whereas cardiovascular diseases cause death and disability among diabetic patients. Accurate measurement of HbA1c levels play an important role on assessment of diagnostic and therapeutic processes of patients.

Hemoglobin variants, especially thalassemia minor are common in our country. Due to cardiovascular effects of diabetes, acetylsalicylic acid (ASA) is frequently used by diabetic patients. Diabetic nephropathy causes renal failure and uremia which require hemodialysis.

The aim of the study is to compare the immunoturbidimetry and high performance liquid chromatography(HPLC) methods to determine HbA1c levels of three groups of patients.
} 
Materials and Methods: Three patients with 20 patients are included in this study: The first group of patients were diagnosed with hemoglobinopathy using hemoglobin electrophoresis, the second group of patients who received ASA $100 \mathrm{mg}$ or more daily for at least 6 months and the third group with chronic hemodialysis. Venous blood samples collected from patients with EDTA-containing tubes were analyzed using the Premier Hb 9210 HPLC (Trinity Biotech (USA) and Cobas c501 immunoturbidimetry (Roche - Germany) autoanalyzers.

Results: After comparison immunoturbidimetry with HPLC, HbA1c levels did not differ in all three groups $(\mathrm{p}=0,462, \mathrm{p}=0,065 \mathrm{p}=0,062)$.

Conclusion: Immunoturbidimetry and HPLC are commonly used methods for HbA1c measurements. HbA1c measurements of immunoturbidimetric method have been shown to be strongly correlated with HPLC method. Diseases or drugs which may interfere with HbA1c measurement should be taken in consideration.

Keywords: Hba1c, HPLC, Immunoturbidimetry, Hemoglobinopathy, Uremia, ASA

\section{Giriș}

Tip 2 Diabetes Mellitus (T2DM) dünyadaki en yaygın hastalıklardan biridir $\square 1 \square$ ve KVH'in diyabetik hastalar arasında ölüme ve sakatlığa neden olduğu bilinmektedir

$\square 2,3 \square$. Diyabetik hastalar arasında kötü kontrol edilen kan şekeri düzeyleri mikrovasküler komplikasyonların gelişiminde rol oynamaktadır ve artmış glikolize hemoglobin $(\mathrm{HbA} 1 \mathrm{c})$ düzeyinin $\mathrm{KVH}$ 'larda risk faktörü olduğu bildirilmektedir $\square 4]$. Diyabetik ve diyabetik olmayan kohortlar dahil olmak üzere yapılan popülasyon bazlı çalışmalarda $\square 3$ ], HbA1c'nin tüm nedenlere bağlı ölümler ve KVH'lara bağlı ölümlerin bağımsız bir belirleyicisi olarak kabul edildiği rapor edilmiștir $\square 5$ ]. Diyabetli bireyler arasında, HbA1c'deki her \%1'lik artış, tüm nedenlere bağlı ölümlerde\% 30'luk bir artış ve KVH ölümlerinde \% 40'lık bir artışla ilişkilidir $\square 6]$.

HbA1c testi, önceki 2-3 ay boyunca kırmızı kan hücrelerinin ömrü boyunca süren geri dönüşümsüz şekilde glikozlanmış hemoglobin molekülünün bir ölçümüdür $\square 7$ ]. Teşhis ve tedavi için diyabet algoritmalarında tartışılmaz bir testtir $\square$ 1]. Rutin HbA1c testlerinin çoğu, NGSP (ABD) ve diğer programlar [Japonya, İsveç) gibi yerel standardizasyon programlarından birine göre standardize edilmiştir. Yine de, HbA1c testlerinin sonuçları, beraberindeki klinik karar limitleri gibi, oldukça farklıdır [8]. HbA1c standardizasyonundaki IFCC Çalışma Grubu, bir referans metodu geliştirmiştir ve ayrıca analitin $\alpha-\mathrm{N}$ glikanlanmış hemoglobin olarak tanımlandığı HbA1c için bir referans sistemi kurmuştur.

Bugün hekimlerin ve hastaların karşılaştığı HbA1c sonuçlarındaki büyük farklılığı sona erdirmek için IFCC referans sisteminin HbAlc için dünya çapında uygulanması önerilmektedir [9]. HbA1c'nin ilk ticari ölçüm yöntemlerinin temeli, Trivelli ve arkadaşların [10] katyon değişim kromatografisiyle HbA1c'yi HbA0'dan ayırmak için kullandıkları yöntemdir. Günümüzde başlıca HbA1c yöntemleri arasında katyon değişim kromatografisi, afinite kromatografisi ve immünoturbidimetri bulunmaktadır.

Bununla birlikte, HbA1c analizi çeşitli hastalıklardan ya da genetik varyasyonlardan etkilenebilmektedir [11]. Dünyada HbA1c seviyelerini etkileyen en yaygın ve en önemli faktörler arasında hemoglobinopatiler (kullanılan yönteme bağlı olarak), bazı anemiler ve sıtma gibi hızlanmış kırmızı hücre turnoverı ile ilişkili bozukluklar bulunmaktadır [12]. Ülkemizde akraba evliliklerinin de sık olmasının etkisiyle başta $\square$ talasemi olmak üzere hemoglobin varyantları yaygın olarak saptanmaktadır [13]. Diyabetin kardiyovasküler etkileri nedeniyle diyabetikler arasında asetil salisilik asit (ASA) yaygın olarak kullanılmaktadır ve diyabetik nefropati son dönemde hemodiyaliz gerektiren böbrek yetmezliğine ve üremiye neden olduğundan [2], bu hasta gruplarında HbA1c ölçümünün en doğru ve en iyi yöntemle yapılması tedavinin izlemi ve yönetimi için çok önemlidir.

\section{Materyal ve Metod}

Bu çalışmada hemoglobinopatili, üremik ve ASA kullanan hastaların HbAlc düzeyleri immünoturbidimetri ve HPLC yöntemlerini kullarak ölçülmüştür.

Çalışma protokolü yerel etik kurul tarafindan onaylandıktan sonra çalışmaya başlanmıştır. American Diabetes Association (ADA) tanı kriterlerine [1] göre tip 2 diyabet tanısı alan, ayrı ayrı 20 kişilik 3 hasta grubu çalışmaya dahil edilmiştir. İlk grup hemoglobin elektroforezi kullanılarak "hemoglobinopati" tanıs1 alan hastalardan, ikinci grup en az 6 aydır günde $100 \mathrm{mg}$ veya üzerinde ASA alan hastalardan ve üçüncü grup kronik hemodiyalize giren ve serum üre düzeyi $50 \mathrm{mg} / \mathrm{dl}$ nin üzerinde olan hastalardan oluşmuştur. Hasta gruplarında yaş ve cinsiyet dağılımı açısından fark bulunmamaktadır. Hastaların gruplandırma sürecinde hemoglobinopati, ASA kullanımı, üremi dışında HbA1c analizini etkileyecek hastalığı olanlar ya da ilaç kullananlar çalışma dışı bırakılmıştır. Hastalardan alınan venöz kan örnekleri EDTA içeren tüplere konarak Premier Hb 9210 (Trinity Biotech-USA) ve Cobas c501 (Roche-Almanya) cihazları kullanılarak analizedilmişti. Tüm örnekler örnek alımını takiben aynı gün içinde analiz edilmiştir.

İstatistiksel analizlerde NCSS (Number Cruncher Statistics System) 2007 istatistik yazılımı cep programı kullanılmıştır. Verilerin değerlendirilmesinde ortalama ve standart sapmaya ek olarak ANOVA, Tukey çoklu karşılaştırma testi ve Ki-Kare testi kullanılmıştır. 0,05 'ten düşük $\mathrm{P}$ değerleri istatistiksel olarak anlamlı kabul edilmiştir. 


\section{Bulgular ve Tartışma}

İlk grupta hemoglobinopatili 20 hastanın HbA1c düzeyleri karşılaştırıldığında, HbA1c ölçümleri arasında iki yöntem arasında istatistiksel olarak anlamlı farklılık gözlenmemiştir ( $\mathrm{p}=0,462)$ (Tablo 1).

Tablo 1: Hemoglobinopatili hastalarda HbA1c karşılaştırilmasi

\begin{tabular}{|l|c|c|}
\hline & Ort \pm SS & p \\
\cline { 1 - 2 } HPLC & $6.21 \pm 0.59$ & \multirow{2}{*}{0.462} \\
\hline Immünoturbidimetri & $6.28 \pm 0.54$ & 0.462 \\
\hline
\end{tabular}

Tablo 2: Hemoglobinopatili hastalarda sınıf içi korelasyon analizi

\begin{tabular}{|c|c|c|c|}
\hline & \multirow{2}{*}{$\begin{array}{c}\text { Intraclass } \\
\text { Correlation } \\
\text { Coefficient } \\
\end{array}$} & \multicolumn{2}{|c|}{ \%95 Güven Aralığı } \\
\hline & & Alt Sinır & Üst Sınır \\
\hline $\begin{array}{l}\text { HPLC } \\
\text { Immünoturbidim } \\
\text { etri }\end{array}$ & 0.935 & 0.926 & 0.927 \\
\hline
\end{tabular}

HPLC ve immünoturbidimetrik yöntemle ölçülen HbA1c analizlerinin sınıfiçi korelasyon katsayısı 0,935 (0,926-0,927) bulunmuştur. Her iki yöntem arasında güçlü bir korelasyon mevcuttur (Tablo 2)

Diğer bir grupta , üre seviyesi $50 \mathrm{mg} / \mathrm{dl}$ 'den yüksek olan 20 kronik hemodiyaliz hastasının HbAlc düzeyleri iki farklı yöntem ile değerlendirilmiştir (HPLC ve immünoturbidimetri) ve iki yöntem arasında istatistiksel olarak anlamlı bir farklılık gözlenmemiştir $(\mathrm{p}=0,065)$ (Tablo3).

Tablo 3: Üremik hastalarda HbA1c karşılaştırılması

\begin{tabular}{|l|c|c|}
\hline & Ort \pm SS & p \\
\hline HPLC & $6.21 \pm 1.26$ & \\
\cline { 1 - 2 } Immünoturbidimetri & $6.06 \pm 1.11$ & 0.065 \\
\hline
\end{tabular}

Tablo 4: Üremik hastalarda sınıf içi korelasyon analizi

\begin{tabular}{|l|l|l|l|}
\hline & & \multicolumn{3}{|c|}{$\begin{array}{l}\text { Güven } \\
\text { Aralı̆̆ı }\end{array}$} \\
\cline { 3 - 4 } & $\begin{array}{l}\text { Intraclass } \\
\text { Correlation } \\
\text { Coefficient }\end{array}$ & Alt Sınır & $\begin{array}{l}\text { Üst } \\
\text { Sınır }\end{array}$ \\
\hline $\begin{array}{l}\text { HPLC } \begin{array}{l}\text { Immünoturbidi } \\
\text { metri }\end{array} \\
\text { metrien }\end{array}$ & 0.986 & 0.966 & 0.994 \\
\hline
\end{tabular}

HPLC ve immünoturbidimetri yöntem kullanılarak ölçülen HbA1c sonuçlarının sınıfiçi korelasyon katsayısı 0,986 $(0,966-0,994)$ bulunmuştur. Her iki yöntem arasında güçlü bir korelasyon mevcuttur (Tablo 4).

Son grupta en az 6 aydır $100 \mathrm{mg} / \mathrm{dl}$ 'den fazla ASA kullanan 20 hastanın HbA1c düzeyleri 2 farklı yöntem ile değerlendirilmiştir. Bu grupta da HbAlc ölçümleri arasında istatistiksel olarak anlamlı farklılık gözlenmemiştir ( $\mathrm{p}=0,062)$ (Tablo5).
Tablo 5: ASA kullanan hastalarda HbA1c karșılaștırılması

\begin{tabular}{|l|c|c|}
\hline & Ort \pm SS & p \\
\hline HPLC & $7.46 \pm 2.59$ & \\
\cline { 1 - 2 } Immünoturbidimetri & $7.08 \pm 2.17$ & 0.062 \\
\hline
\end{tabular}

Tablo 6: ASA kullanan hastalarda sınıfiçi korelasyon analizi

\begin{tabular}{|l|l|l|l|}
\hline & $\begin{array}{l}\text { Intraclass } \\
\text { Correlation } \\
\text { Coefficient }\end{array}$ & \%995 Güven Aralığı \\
\cline { 3 - 4 } & & Alt Sınır & Üst Sınır \\
\hline HPLC & & & \\
$\begin{array}{l}\text { Immünoturbidi } \\
\text { metri }\end{array}$ & 0.986 & 0.943 & 0.996 \\
\hline
\end{tabular}

Premier ve COBAS cihazlarının HbA1c ölçümlerinin sınıfiçi korelasyon katsayısı 0,986 (0,943-0,996) bulunmuştur. Her iki yöntem arasında güçlü bir korelasyon mevcuttur (Tablo 6). Küresel obezite salgını nedeniyle önümüzdeki yıllarda diabetes mellitus ve KVH'ların artması beklenmekte [14] ve Türkiye'de yapılan çalışmalar ülkemizin diyabet sıklığı artan ülkeler arasında olduğunu desteklemektedir [15].

KVH'ların diyabetli hastalarda en büyük ölüm nedeni olduğu bilinmektedir [16]. Çalışmalar, yoğun glisemik kontrolün, T2DM hastalarda mikrovasküler komplikasyon riskini azalttığına işaret ederken [17-19], HbAlc ve KVH arasındaki ilişki daha net tanımlanmış$\operatorname{tir}[20,21]$.

HbA1c düzeylerinin gruplara göre sinıflandırıldığ çalışmada $\mathrm{HbA1c}$ düzeyindeki her $\% 1$ lik düşüşün $\mathrm{KVH}$ oranında \%18 lik bir düşüş ile ilişkili olduğu görülmüştür [16].

ADA, 2009'dan beri, uzun süreli glisemik kontrolün izlenmesinin yanı sıra, Diabetes Mellitus'un teşhisi için HbA1c seviyelerinin değerlendirilmesini önermektedir [22, 23]. Yani HbA1c ölçümü diyabetik hastalarda tanı, prognoz ve hasta takibinde izlenecek stratejiyi belirlemede yol gösterici olduğundan doğru ölçülmesi çok önemlidir. HbAlc ölçümü açlık gerektirmemekte, sadece bir kan örneğine ihtiyaç duymakta ve aylık ortalama glisemik seviyeyi yansıtmaktadır, ancak aynı zamanda bazı hastalıklardan ya da ilaçlardan etkilenme ve yöntem standardizasyonu gibi çeşitli sınırlamaları bulunmaktadır [24].

Bu çalışmada özellikle hemoglobinopatili, ASA kullanan ve üremik hastaların $\mathrm{HbAlc}$ analizleri yapılarak, sık karşılaşılan bu durumların HbA1c analizini üzerine olan etkisinin araştırılması amaçlanmıştır.

HbA1c analizinde kullanılan en eski yöntem, HbA1c'yi HbA0'dan ayırmak için reçineyi kullanan iyon değişimi kromatografi yöntemidir [25]. Glikoz ile hemoglobinin beta zincirindeki $\mathrm{N}$ terminal amino asit valini arasında enzimatik olmayan bir reaksiyon olan glikasyon, ayırma için gerekli olan HbA1c izo-elektrik noktasında küçük bir değişiklik meydana getirir. Daha spesifik reçinelerin 
geliştirilmesi daha iyi ayrılma sağlar. İkinci bir yöntem, aynı glikasyon bölgesi olan hemoglobinin beta terminali, immünoturbidimetri tarafından tanınır, ne yazık ki ilgili primer veya sekonder referans materyalinin bulunmaması, spesifik olmayan katyon değişim kromatografisine geri kalibrasyon gerekliliğine yol açar. Üçüncü bir yöntem [26], high-performance liquid chromatographic (HPLC), hemoglobinin alfa - N terminalleri ve epsilon kalıntıları üzerindeki glikasyonun yanı sira beta-N terminaline spesifik glikasyonu ölçer. Glikozlanmış hemoglobin bağının 1,2cis diol grupları geri dönüşümlüdür ve özellikle boronat, afinite nedeniyle bir ayrılma ile sonuçlanır. Bu yöntemin toplam bağlanması benzersizdir ve herhangi bir karışma rapor edilmemiştir. [27]. İmmünoturbidimetri ve boronat afinite yöntemleri, sirasiyla NGSP (National Glycohemoglobin Standardization Program) ve IFCC (International Federation of Clinical Chemistry) düzenlemelerine göre standartlaştırılmıştır.

Günümüzde immünoturbidimetri ve HPLC yöntemleri dünya çapında sıklıkla kullanılmakta olan 2 yöntemdir. NGSP, tüm metotların birbirinin yerine kullanılabileceğini bildirmektedir. HPLC yöntemleri (katyon değişimi, boronat afinitesi)

immünoturbidimetriden daha pahalıdır ve bu yöntemler özel ekipmanlar gerektirir. Bu yöntemin dezavantajları, laboratuvarda ek bir analiz alanı gerekliliği, eğitimli personel gerektirmesi ve o analizörde ek bir test çalışılamamasıdır. İmmünoturbidimetri yöntemi ise kimyasal bir otoanalizörün bir parçasıdır ve kimyasal analiz sırasında eş zamanlı olarak ölçümler yapılabilir. Yeni jenerasyon immünoturbidimetri sistemleri manuel olarak hemolizat preparatı gerektirir ve maliyeti daha düşüktür, ancak aynı anda sınırlı sayıda örnek invertörü ve diğer kimya testlerinin birlikte ölçümü, laboratuvar personelinin toplamda çalışmasını zorlaştırmaktadır.

Yapısal değişkenlerin ve hemoglobinin kimyasal türevlerinin HbA1c analizini etkilediği bildirilmiş [23] ve hemoglobinin yüzlerce genetik varyant1 tanımlanmıştır [28]. Varyantların çoğu $\alpha, \beta, \gamma$ veya $\delta$ zincirlerinde nokta mutasyonu sonucu oluşmuştur [29,30]. En yaygın karşılaşılan hemoglobinopatiler $\mathrm{HbC}$ ve $\mathrm{HbS}, \beta$-talasemiler olmakla birlikte[31], bu durumun birçok immünoassay yöntemini etkilediği gösterilmiştir $[23,32]$.Yapılan bazı çalışmalarda $\mathrm{HbF}$, HbGraz ve HbRaleigh'in immünoassay yöntem ile HbAlc değerlerini düşürdüğü bildirilmiş [33-34], ancak Bry ve arkadaşları HbA1c testlerinin (immunoassay,katyon değişim kromatografisi ve boronat afinitesi) toplam hemoglobinin \% 5 'in altındaki HbF konsantrasyonundan etkilenmediğini göstermiştir [23]. $\beta$-talasemilerin Türkiye'de \% 2,1 olduğu rapor edilmiş olup, Türkiye'de akraba evliliğinin varlığı hemoglobinopatilerin sıklığını arttırmaktadır [13]. Bu çalışmada hemoglobinopati olarak $\beta$ talasemiler seçilmiştir. HbF seviyesi, özellikle ülkemizde sık görülen talasemi minörün de yaklaşı $\%$ 20'sidir [35]. Bu nedenle $\mathrm{HbF}$, Türkiye'de etkileşime girmesi göz önünde bulundurulması gereken önemli hemoglobin varyantlarından biridir.

$\mathrm{Hb}$ varyantları ve türevlerinin HLPC yöntemiyle [29,36] HbA1c ölçümünde etkileşime neden olmadığ bildirilmiştir. Çalışmamızda immunoturbidimetrik yöntem ile HPLC arasında güçlü bir korelasyon saptanmıştır. Genç ve arkadaşları çalışmamızı destekleyen sonuçlar elde etmişler ve hemoglobin varyantlarının immünoassay yöntemine [37] müdahale etmediği ve etkileşime girmediği bildirilmiştir.

Bizim çalışmamızda ise yukarıda bahsedilen çalışmalardan farklı olarak hemoglobinopatisi olan grupta yani $\mathrm{HbF} \% 5$ 'in üzerinde olan grupta da $\mathrm{HbAlc}$ ölçümünde iki metod arasında anlamlı bir farklılık görülmemiştir ( $\mathrm{p}=0,462)$.

Bazı çalışmalar karbamil hemoglobinin toplam hemoglobine oranın üremik hastalarda olduğunu göstermiştir, karbamil hemoglobin HbA1c'ye benzer bir izoelektrik noktaya sahiptir. Bu nedenle, karbamil hemoglobin oranı \% 5.4'ten daha yüksek olması hatalı olarak yüksek HbAlc sonuçlarına neden olmaktadır [38]. Oysa bizim çalışmamızda üre seviyesi 50 $\mathrm{mg} / \mathrm{dl}$ 'den yüksek kronik hemodiyalize giren T2DM hastalarında $\mathrm{HbAlc}$ ölçümünde iki metod arasında anlamlı bir farklılık görülmemiştir $(\mathrm{p}=0,065)$.

Diyabetin KVH'larla birlikteliği nedeniyle T2DM hastalarında ASA kullanımı sıktır. Yapılan çalışmalar göstermiştir lki günde 1 gr'dan daha az ASA alımı, in vitro koşullarda asetillenmiş hemoglobin üretir [39]. Asetillenmiş hemoglobin HbA1c ölçümlerinde yanlış düşük HbAlc sonuçlarına yol açan bir faktördür. Yaptığımız çalışmada 6 aydan uzun süredir en az 100 mg ASA kullanan grupta HbA1c ölçümünde iki metod arasında anlamlı bir farklılık görülmemiştir $(\mathrm{p}=0,062)$. Yani ASA kullanımı HbA1c ölçümünü etkilememiştir.

\section{Sonuç}

HbA1c düzeyleri farklı yöntemlerle analiz edilebilmektedir. En uygun yöntem hassas, düşük maliyetli ve kolay uygulanabilir olan yöntem olmalıdır [40].

İmmünoturbidimetrik yöntemlerin $\mathrm{HbA} 1 \mathrm{c}$ ölçümlerinde HPLC yöntemleriyle arasında güçlü bir korelasyon olduğu gösterilmiştir. Her iki yöntemin de, göz önünde bulundurması gereken avantaj ve dezavantajları var olup, yöntemlerin analitik tutarsızlıkları ve maliyet etkinlikleri doğru kararı vermek için yeterli değildir. Hemoglobin sentezini etkileyen hemoglobinopatiler, genetik hastalıkların sıklığı ile ilgili popülasyon özellikleri, üremiye neden olan kronik böbrek yetmezliği gibi hastalıkların varlığı ve çoklu ilaç tedavisi alan hastaların da dikkate alınması gerektiği unutulmamalıdır. Seçilen yöntemin hatalı sonuçlarından kaçınmak için tüm bu faktörler dikkatlice araştırılmalıdır.Çalışmamız her ne kadar immünoturbidimetrik yöntem ile HPLC yönteminin arasında güçlü bir korelasyon olduğu göstermiş olsa da, 
interferans açısından daha fazla sayıda ve özellikte hastalar üzerinde çalışmalar yapılması gerekmektedir.

\section{Kaynaklar}

1. American Diabetes Association. 2. Classification and Diagnosis of Diabetes: Standards of Medical Care in Diabetes2018, Diabetes Care, 2018, 41(Suppl 1), 13-27.

2. Gray, S, P, Jandeleit-Dahm, K, The pathobiology of diabetic vascular complications--cardiovascular and kidney disease, The Journal of Molecular Medicine, 2014, 92(5), 441-452.

3. Cleland, S, J, Cardiovascular risk in double diabetes mellituswhen two worlds collide, Nature Reviews Endocrinology, 2012, 10, 8(8), 476-485.

4. Zhang, P, Y, Cardiovascular disease in diabetes. European Review for Medical and Pharmacological Science, 2014 18(15), 2205-2214

5. Aneja, A, Tang, W, H, Bansilal, S, Garcia, M, J, Farkouh, M E, Diabetic cardiomyopathy: insights into pathogenesis, diagnostic challenges, and therapeutic options. The American Journal of Medicine, 2008, 121(9),748-57.

6. Khaw, K, T, Wareham, N, Bingham, S, Luben, R, Welch, A Day, N, Association of hemoglobin A1c with cardiovascular disease and mortality in adults: the European prospective investigation into cancer in Norfolk, Annals of Internal Medicin, 2004, 21, 141(6), 413-420.

7. Krishnamurti, U, Steffes, M, W. Glycohemoglobin: a primary predictor of the development or reversal of complications of diabetes mellitus. Clinical Chemistry, 2001, 47(7), 1157-1165.

8. Miedema, K, Towards worldwide standardisation of HbA1c determination, Diabetologia, 2004, 47(7), 1143-1148.

9. Hoelzel, W, Weykamp, C, Jeppsson, J, O, Miedema, K, Barr J, R, Goodall, I, Hoshino, T, John, W, G, Kobold, U, Little, R, Mosca, A, Mauri, P, Paroni, R, Susanto, F, Takei, I, Thienpont, L, Umemoto, M, Wiedmeyer, H, M, IFCC Working Group on HbA1c Standardization. IFCC reference system for measurement of hemoglobin A1c in human blood and the national standardization schemes in the United States, Japan, and Sweden: a method-comparison study, Clinical Chemistry, 2004, 50(1), 166-174.

10. Trivelli, L, A, Ranney, H, M, Lai, H, T, Hemoglobin components in patients with diabetes mellitus, The New England Journal of Medicine, 1971, 18, 284(7), 353-357

11. Ma R, C, Chan, J, C, Type 2 diabetes in East Asians: similarities and differences with populations in Europe and the United States, Annals of the New York Academy of Sciences, 2013, 1281, 64-91.

12. Use of Glycated Haemoglobin (HbA1c) in the Diagnosis of Diabetes Mellitus: Abbreviated Report of a WHO Consultation. Geneva, World Health Organization, 2011. PubMed PMID: 26158184.

13. Canatan, D, Thalassemias and hemoglobinopathies in Turkey. Hemoglobin, 2014, 38(5), 305-307.

14. Olshansky, S, J, Passaro, D, J, Hershow, R, C, Layden, J, Carnes, B, A, Brody, J, Hayflick, L, Butler, R, N, Allison, D, B, Ludwig, D, S, A potential decline in life expectancy in the United States in the 21st century. The New England Journal of Medicine, 2005, 17, 352(11), 1138-1145

15. Satman, İ, TURDEP-II Çalışması ilk sonuçlar, 32.TEMH Kongresi, 13-17 Ekim 2010, Antalya Kongre Kitabı, 2010, 12.

16. Skyler, J, S, Bergenstal, R, Bonow, R, O, Buse, J, Deedwania P, Gale, E, A, Howard, B, V, Kirkman, M, S, Kosiborod, M, Reaven, P, Sherwin, R, S, American Diabetes Association American College of Cardiology Foundation; American Heart Association, Intensive glycemic control and the prevention of cardiovascular events: implications of the ACCORD, ADVANCE, and VA Diabetes Trials: a position statement of the American Diabetes Association and a Scientific Statement of the American College of Cardiology Foundation and the American Heart Association, Journal of the American College of Cardiology, 2009, 20, 53(3), 298-304.

17. Ohkubo, Y, Kishikawa, H, Araki, E, Miyata, T, Isami, S, Motoyoshi, S, Kojima, Y, Furuyoshi, N, Shichiri, M Intensive insulin therapy prevents the progression of diabetic microvascular complications in Japanese patients with noninsulin-dependent diabetes mellitus: a randomized prospective 6-year study, Diabetes Research and Clinical Practice, 1995, 28, 103-117.

18. The UK Prospective Diabetes Study (UKPDS) Group. Effect of intensive blood-glucose control with metformin on complications in overweight patients with type 2 diabetes (UKPDS 34), Lancet, 1993, 352, 854-865.

19. The UK Prospective Diabetes Study (UKPDS) Group, Intensive blood-glucose control with sulphonylureas or insulin compared with conventional treatment and risk of complications in patients with type 2 diabetes (UKPDS 33), Lancet, 1998, 352, 837-853.

20. Selvin, E, Marinopoulos, S, Berkenblit, G, Rami, T, Brancati, F, L, Powe, N, R, Golden, S, H, Meta-Analysis: Glycosylated Hemoglobin and Cardiovascular Disease in Diabetes Mellitus, Annals of Internal Medicine, 2004, 141, 421-431.

21. Stettler, C, Allemann, S, Jüni, P, Cull, C, A, Holman, R, R, Egger, M, Krähenbühl, S, Diem, P. Glycemic control and macrovascular disease in types 1 and 2 diabetes mellitus: meta-analysis of randomized trials, American Heart Journal, 2006, 152, 27-38

22. American Diabetes Association. Standards of medical care in diabetes - 2010, Diabetes Care, 2010, 33(Suppl 1), 11-61.

23. Bry, L, Chen, P, C, Sacks, D, B, Effects of hemoglobin variants and chemically modified derivatives on assays for glycohemoglobin, Clinical Chemistry, 2001, 47(2), 153-163. Erratum in: Clinical Chemistry, 2001, 47(6), 1141.

24. Sofronescu, A, G, Williams, L, M, Andrews, D, M, Zhu, Y Unexpected hemoglobin A1c results, Clinical Chemistry, 2011, 57(2), 153-156.

25. McDonald, M, J, Shapiro, R, Bleichman, M, Solway, J, Bunn, H, F, Glycosylated minor components of human adult hemoglobin. Purification, identification, and partial structural analysis, The Journal of Biological Chemistry, 1978, 10 253(7), 2327-2332.

26. Mallia, A, K, Hermanson, G, J, Krohn, R, I, Fujimoto, E, K Smith, P, K, Preparation and use of a boronic acid affinity support for separation and quantitation of glycosylated haemoglobin, Analytical Letters, 1981, 14, 649-661.

27. Miedema, K, Towards worldwide standardisation of HbA1c determination, Diabetologia, 2004, 47(7), 1143-1148

28. Anonymous, International Hemoglobin Information Center variant list, Hemoglobin, 1994, 18, 77-183.

29. Frank, E, L, Moulton, L, Little, R, R, Wiedmeyer, H, M Rohlfing, C, Roberts, W, L, Effects of hemoglobin C and S traits on seven glycohemoglobin methods, Clinical Chemistry, 2000, 46, 864-867.

30. Schnedl, W, J, Trinker, M, Lipp, R, W, HbA1c determinations in patients with hemoglobinopathies, Diabetes Care, 1999, 22, 368-369.

31. Reid, H, Famodu, A, A, Photiades, D, P, Osamo, O, N, Glycosylated haemoglobin $\mathrm{HbA} 1 \mathrm{c}$ and $\mathrm{HbS} 1 \mathrm{c}$ in non-diabetic Nigerians, Tropical and Geographical Medicine, 1992, 44, 131-134.

32. Sacks, D, B, Hemoglobin variants and hemoglobin A1c analysis: problem solved, Clinical Chemistry, 2003, 49, 12451247.

33. Chen, D, Crimmins, D, L, Hsu, F, F, Lindberg, F, P, Scott, M $\mathrm{G}$, Hemoglobin Raleigh as the cause of a falsely increased hemoglobin A1c in an automated ion-exchange HPLC method, Clinical Chemistry, 1998, 44, 1296-301.

34. Schnedl, W, J, Reisinger, E, C, Pieberm, T, R, Lipp, R, W, Schreiber, F, Hopmeier, P, Krejs, G, J, Hemoglobin Sherwood Forest detected by high performance liquid chromatography for hemoglobin A1c, Hematopathology, 1995, 104, 444-446

35. Genc, S, Omer, B, Aycan-Ustyol, E, Ince, N, Bal, F, Gurdol, $\mathrm{F}$, Evaluation of turbidimetric inhibition immunoassay (TINIA) and HPLC methods for glycated haemoglobin determination, Journal of Clinical Laboratory Analysis, 2012, 26(6), 481-485.

36. Roberts, W, L, McCraw, M, Cook, C, B, Effects of sickle cell trait and hemoglobin $\mathrm{C}$ on determinations of HbA1c by an immunoassay method, Diabetes Care, 1998, 21, 983-986.

37. Chachou, A, Randoux, C, Millart, H, Chanard, J, Gillery, P, Influence of in vivo haemoglobin carbamylation on $\mathrm{HbA} 1 \mathrm{c}$ measurements by various methods, Clinical 
Chemistry and Laboratory Medicine, 2000, 38, 321-326.

38. Miedema, K, Electrospray mass spectroscopy for measurement of glycohemoglobin, Clinical Chemistry, 1997, 43, 705-707.

39. Weykamp, C, W, Penders, T, J, Siebelder, C, W, Muskiet, F, A, van der Slik, W, Interference of carbamylated and acetylated hemoglobins in assays of glycohemoglobin by HPLC, electrophoresis, affinity chromatography, and enzyme immunoassay, Clinical Chemistry, 1993, 39, 138-142.

40. Halwachs-Baumann, G, Katzensteiner, S, Schnedl, W, Pürstner, P, Pieber, T, Wilders-Truschnig, M, Comparative evaluation of three assay systems for automated determination of hemoglobin A1c, Clinical Chemistry, 1997, 43(3), 511-7.

http://edergi.cbu.edu.tr/ojs/index.php/cbusbed isimli yazarın CBU-SBED başlıklı eseri bu Creative Commons Alıntı-Gayriticari4.0 Uluslararası Lisansı ile lisanslanmıştır 